\title{
External Environment Analysis of Commercial-use drones
}

\author{
Zhiyao He \\ School of North China Electric Power University, Hebei 071003, China \\ 503980454@qq.com
}

Keywords: Business environment; GPS App; Commercial-use drones.

\begin{abstract}
The main purpose of this report is to analyze the external business environment for a research group that has developed a fantastic GPS technology. This group wants their technology to be used on commercial-use drones so the estimates of UK drones market in this year and next three years will be shown and two factors of PESTEL tool is used to analyze the market. In the introduction, this report has shown the estimates of the UK drones market according to the requirement. Legal factor and environmental factor are used in the PESTEL analysis next. From the discussion, environmental factor gives a positive effect on the market because not only the drones themselves are friendly to the environment, but they can also be used in lots of applications which are helpful in environment protection. On the other hand, legal factor affect it negatively for the laws has limited the use of drones, leading an increase of use cost. Finally, another opportunity is mentioned for this GPS group, which is mobile navigation app market. This market will keep increasing for their significant positions on travelling, outdoor learning and ensuring safety.
\end{abstract}

\section{Introduction}

In this part I give a brief estimate for the UK drone market size (in £s) in these years, the analysis using PESTEL tools is given in next part and finally an discussion about another opportunity for the GPS technology is given as conclusion.

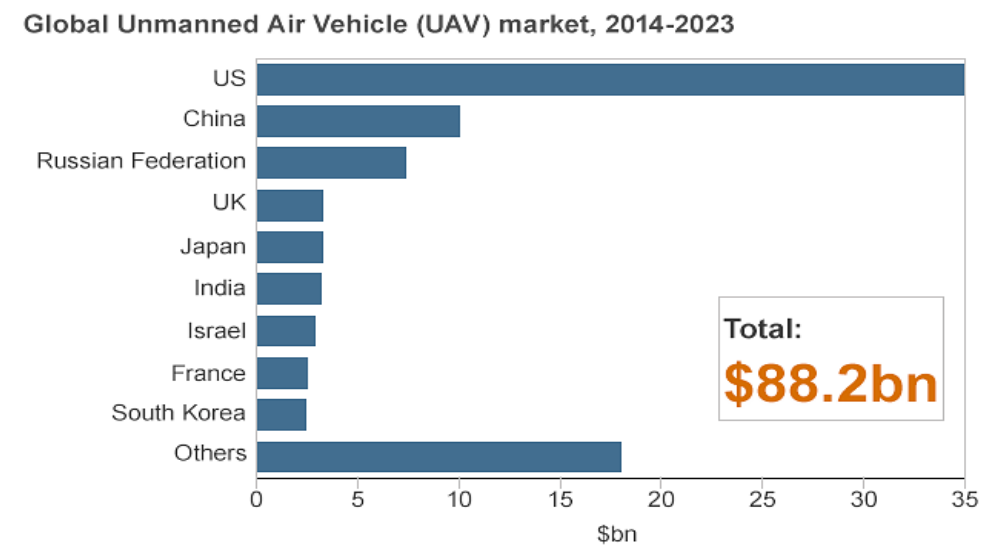

Fig. 1 Global Unmanned Air Vehicle market, 2014-2023

Figure one shows that from 2014 to 2023 , the UK unmanned air vehicle market account for around $3.6 \%$ in the whole world market.

On the other hand, although the drones market for civilian use is much less than the defense part, we can still see a relatively slow increase for global civilian market. According to the data we have got, from 2015 to 2018 the global drones market for civilian is $\$ 0.6 \mathrm{bn}, \$ 0.9 \mathrm{bn}, \$ 1.2 \mathrm{bn}$ and $\$ 1.21 \mathrm{bn}$. If we use the average exchange rate from pounds to dollars in past five years, which is $1.51^{[1]}$ and assume that the global economy will not have a dramatically change, we can treat the global market as $£ 0.4 \mathrm{bn}$, $£ 0.6 \mathrm{bn}, £ 0.8 \mathrm{bn}, £ 0.806 \mathrm{bn}$ in these four years. Based on the proportion we calculate before, the UK commercial-use drones market from 2015 to 2018 can be deduced as $£ 14.3 \mathrm{~m}, £ 21.46 \mathrm{~m}, £ 28.6 \mathrm{~m}$, and $£ 28.85 \mathrm{~m}$. 


\section{PESTEL analysis}

I use environmental factor and legal factor to analyze the market of the drones in UK.

\subsection{Environmental factors}

Environmental investment of UK government. The UK government has spent $£ 25$ billion on housing and environment for 2014 to 2015 , which is about $3.5 \%$ of the total spend ${ }^{[2]}$. This ratio may keep stable these years and because of the increasing of the total spend, the money that UK government spend for environment protection may become more in the future ${ }^{[3]}$. Based on this, more efficiency and advanced environmental protection methods are required. The application of drones is one of them.

Applications of drones to protect environment. The drones themselves are friendly to environment because they do not pollute the air and only use electric energy. Using the drones to inspect forests can help us find any danger promptly. Besides, the daily amount that one generic tree planter can plant is 1500 , which is less than $10 \%$ of using new technology of drones and according to the calculation, a billion trees can be planted one year if we use 100 teams of drones ${ }^{[4]}$.From the Natural Environment White Paper, the UK government will be committed to provide more efforts to protect woodlands, so the use of drones on this situation may increase ${ }^{[5]}$.

Not only the drones can be used in inspection of woodlands, they can also observe the wildlife because the flexibility guarantees the observation in the places that humans may not arrive. Actually WWF plans to use drones to protect wildlife and will test two pairs of drones by $2015^{[6]}$.

Drones also help with the agriculture, based on data that the drones collected, the management zone map can be developed and according to this, farmers can save $40 \%$ resource in every acre, which is about 20 tons fertilizer ${ }^{[7]}$.

The importance. The health of environment is the fundament of the human lives, being friendly to environment is the premise that one product will be universal. We gradually find that the drones can be used in plenty of positive applications for environment, and this will get the support of the government, which means the efficiency and flexibility will give a growing market for drones when it is used for environment.

\subsection{Legal factors}

Safety rules of using drones. According to the CAA requirement, if there is any person within 50 meters, the drones cannot be flown except during taking-off and landing, and this limitation is same for vessels, vehicles and structures ${ }^{[8]}$. Because of these laws, the implementing for commercial-use of drones becomes more difficult when it needs to fly through city or any other congested area. For the delivery service, the limitation for flexibility and changeability of shipping lines, as well as the dependence for the specific land and take-off site results in a fact that the drones delivery service inferior to traditional delivery service in popularity.

Besides, the operation of drones must be kept within the visual line of sight of people who control it, generally within $500 \mathrm{~m}^{[9]}$. So the aircraft may not be used during night or when the weather is bad and on the other hand, as one kind of traffic tools, the speed will be limited for the safety when it is across the city. Based on these, the efficiency of drones when they are used in urban areas will be highly decreased.

The importance. The limitation of the use for drones results in increasing of use cost. The $85 \%$ of Amazon's items can be delivered through drones ${ }^{[10]}$. However, after we solve all the difficulties of using drones for delivery in city, customers need to pay $£ 60$ to $£ 120$ delivery fee for a five-pound item. The expectation of saving people by using drones are still cannot be implemented in UK because every drone need to be watched by at least one person as we discussed above.

The laws about drones in UK emphasis the public safety, we do not figure out a way to balance the public safety and the cost of the drones, besides, the popularity of using drones in our daily lives is not ideal. In the next few years, the market of drones used in the area that relate to humans life may not as good as environmental application, because of the safety problems. 


\section{Conclusion}

From the PESTEL analysis we find out some negative factors in drones market, which may lead to a significant limitation of implementing the GPS technology on it. On the other hand, GPS can be efficiently used in navigation applications, so mobile navigation apps may be another opportunity that the company should focus on.

\subsection{UK Market Size estimates}

Global Mobile Apps Sector Revenue (\$B)

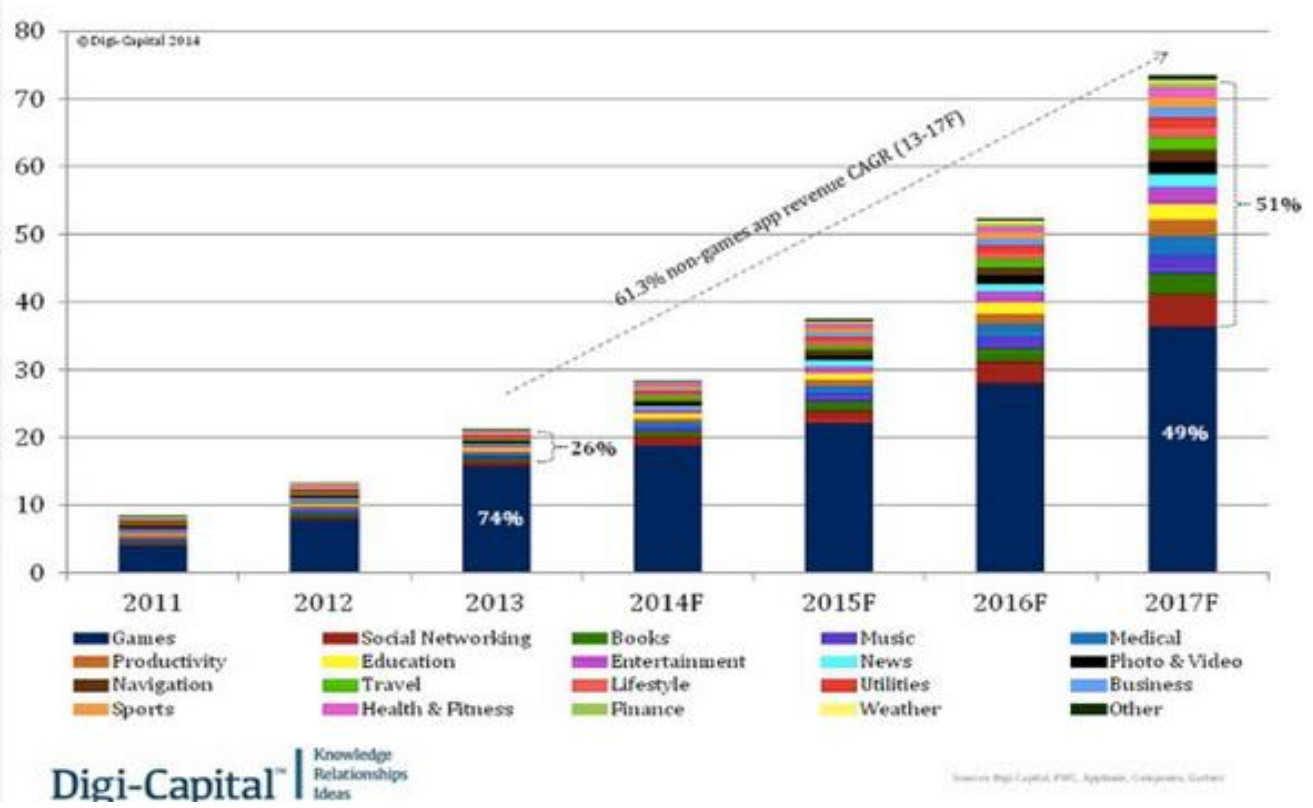

Fig.2 Global Mobile Sector Revenue

Figure 2 shows the global mobile app markets, we can see the navigation apps keeps increasing in these years, and from 2015 to 2017 they are $\$ 1 \mathrm{bn}, \$ 1.5 \mathrm{bn}, \$ 2 \mathrm{bn}$. If we assume the annual change in 2018 is $+42 \%$, which is average increasing percentage during last four years, we can predict the market is $\$ 2.84$ bn in 2018. UK mobile apps market account for 3\% of the global market, and using the 1.51 as the exchange rate we can get from 2015 to 2018 the mobile navigation app market in UK is $£ 19.86 \mathrm{~m}, £ 29.8 \mathrm{~m}, £ 39.74 \mathrm{~m}$ and $£ 56.42 \mathrm{~m}$.

\section{2 positive factors for mobile navigation app market}

There are more than $72 \%$ of people in UK who use smart-phones, and this value tend to be higher in the future, which is the base for the navigation apps popularizing. Since 2000, the United Kingdom households' disposable income has kept a stable increasing, which means that people have more money to ensure them pay more attention on the quality of their life and how to live a healthy life. Traveling may be a good choice. People who do not travel will suffer $20 \%$ higher risk of death and $30 \%$ greater risk of death from heart disease, and after a few days of traveling, people can have a good sleep and will have an $80 \%$ improvement on the reaction time.

On the other hand, a growing number of parents, schools and organizations reach a consensus that children need to experience a wide range of knowledge outside the classroom. And because the safety is highly ensured, parents may tend to spend more time to bring their children to get a learning travel.

As we know, navigation is very important in leading routes and finding places during traveling and mobile apps are more convenient than traditional PNDs, so the mobile navigation app market will experience a positive prospect in the next few years. Besides, mobile navigation apps can be used to ensure the safety of kids, parents can easily know the location of their children who have such mobile phones. 
In conclusion, there are still some problems for the drones in commercial-use when we think about the applications relatively to people. However, the mobile navigation app market for this GPS technology is relatively more mature.

\section{References}

[1] 'Killer robots': Are they really inevitable?' BBC news, 21 May 2014 Available at: < http://www.bbc.co.uk/news/business-27332130>

[2] 'COMMERCIAL DRONES: Assessing the Potential for A New Drone-Powered Economy', MARCELO BALLVE, 13 OCT 2014 Available at: <http://www.businessinsider.com/ the-market-for-commercial-drones-2014-2? IR=T >

[3] 'Environmental Protection', NAO, and June 2014 Available at: < http://www.nao.org. uk/wp-content/uploads/2014/06/Environmental-Protection-briefing.pdf >

[4] 'Eco-Drones Aid Researchers in Fight to Save the Environment', LINDA CARROLL, NBCNEWS, February 20th 2015

[5] G.R. Met tam, L.B. Adams, How to prepare an electronic version of your article, in: B.S. Jones, R.Z. Smith (Eds.), Introduction to the Electronic Age, E-Publishing Inc., New York, 1999, pp. 281-304.

[6] 'Natural Environment White Paper Implementation Update report', Department for Environment Food and Rural Affairs, October 2014 Available at: <https://www.gov.uk/government/uploads /system/uploads/attachment_data/file/366526/newp-imp-update-oct-2014.pdf >

[7] 'WWF plans to use drones to protect wildlife', Adam Vaughan, 7 February 2013 Available at: < http://www.theguardian.com/environment/2013/feb/07/wwf-wildlife-drones-illegal-trade >

[8] 'Agriculture Drones Help Farmers Reduce Resource Use', Hannah Miller, and February 19th, 2015 Available at: < http://www.triplepundit.com/2015/02/agriculture-drones-help-farmersreduce-resource-use/ >

[9] 'SUMMARY OF UK LEGAL REQUIREMENTS', droneflight.com Available at: < http://droneflight.co.uk/pages/summary-of-uk-legal-requirements >

[10] '5 FACTS ABOUT AMAZON'S DELIVERY DRONES', Daniel Price, and February 27, 2014 Available at: < http://cloudtweaks.com/2014/02/5-facts-amazons-delivery-drones/ > . 